archives

of thermodynamics

Vol. 38(2017), No. 4, 15-28

DOI: $10.1515 /$ aoter-2017-0022

\title{
Modeling of pressure drop during refrigerant condensation in pipe minichannels
}

\author{
MAEGORZATA SIKORA* \\ TADEUSZ BOHDAL
}

Koszalin University of Technology, Faculty of Mechanical Engineering, Racławicka 15, 75-900 Koszalin

\begin{abstract}
Investigations of refrigerant condensation in pipe minichannels are very challenging and complicated issue. Due to the multitude of influences very important is mathematical and computer modeling. Its allows for performing calculations for many different refrigerants under different flow conditions. A large number of experimental results published in the literature allows for experimental verification of correctness of the models. In this work is presented a mathematical model for calculation of flow resistance during condensation of refrigerants in the pipe minichannel. The model was developed in environment based on conservation equations. The results of calculations were verified by authors own experimental investigations results.
\end{abstract}

Keywords: Minichannels; Pressure drop; Refrigerant; Condensation

\section{Nomenclature}

\begin{tabular}{|c|c|c|}
\hline$A$ & - & heat transfer area, $\mathrm{m}^{2}$ \\
\hline$B$ & - & correction factor \\
\hline$C$ & - & wetted perimeter, $\mathrm{m}$ \\
\hline$c_{p}$ & - & specific heat, $\mathrm{J} / \mathrm{kg} \mathrm{K}$ \\
\hline$d$ & - & minichannel internal diameter, $\mathrm{m}$ \\
\hline$d_{h}$ & - & hydraulic diameter, m \\
\hline
\end{tabular}

${ }^{*}$ Corresponding Author. Email malgorzata.sikora@tu.koszalin.pl 


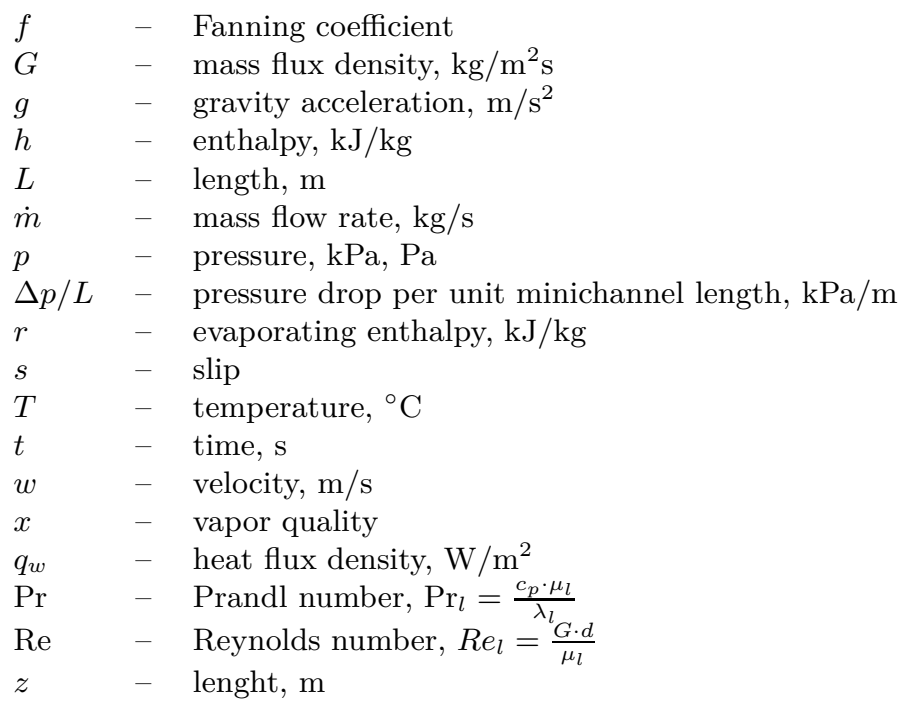

\section{Greek symbols}

$\beta-$ channel inclination angle

$\delta_{H} \quad-\quad$ thickness of the hydraulic boundary sublayer, $\mathrm{m}$

$\varphi \quad-\quad$ void fraction

$\lambda \quad-$ heat conductivity coefficient, $\mathrm{W} / \mathrm{m} \mathrm{K}$

$\rho \quad-\quad$ density, $\mathrm{kg} / \mathrm{m}^{3}$

$\mu \quad-\quad$ dynamic viscosity, $\mathrm{kg} / \mathrm{m} \mathrm{s}$

$\tau_{w} \quad-$ shear stress

\section{Superscripts}

\begin{tabular}{|c|c|c|}
\hline$H$ & - & hydraulic \\
\hline$h$ & - & at constant enthalpy \\
\hline$l$ & - & liquid \\
\hline$p$ & - & at constant pressure \\
\hline$s$ & - & saturation value \\
\hline$v$ & - & vapour \\
\hline$x$ & - & local value \\
\hline$T P F$ & - & two-phase flow \\
\hline
\end{tabular}

\section{Introduction}

Continuous technical progress demands the construction of highly efficient and low-energy machines and equipment. This applies to both high- and low-temperature processes. The analysis of global trends in the development of distributed energy indicates an increasing demand for miniaturized devices carrying large heat flux. There is a need for miniaturization in many 
industries, including electronics, aerospace, telecommunications, medicine, microbiology, etc [11]. Ongoing work related to the improvement of existing devices and the development of new ones is underway in the power sector, as well as for refrigeration and air conditioning applications. There are high hopes associated with the creation and production of highly efficient cogeneration mini electric stations that can produce both electricity and thermal energy for the needs of small, individual customers [14,15]. Advanced work on the implementation of a high efficient mini refrigeration system that can be used to cool the processor for high performance computing is also underway [19]. Thermodynamic cycles, in accordance with the second law of thermodynamics, can be used to complimentary two thermal effects, i.e., the effect of heating or cooling. An important element of these installations is the presence of mini heat exchangers (evaporators and condensers). The use of the refrigerant phase transformations in these situations is essential. However, there is a need to intensify the heat exchange. One of the passive methods of convection heat transfer process intensification, from the side of the working fluid, is to reduce the diameter of the channels in which the refrigerant flows and performs the heat exchange process $[16,21]$. The measure of the intensification effectiveness is the increase of the heat transfer coefficient value. However, this is associated by an increase of flow resistance. In the case of minichannels, this raises a certain calculation problem in the design of mini heat exchangers $[5,6]$. It should be noted that, in the market, there are new types of refrigerants that have different physical and chemical properties, which complicate the calculation procedures.

In recent years, the interest as well as the number of published studies concerning the thermal and flow processes in mini heat exchangers, where the channels used have a smaller internal diameter than conventional channels $\left(d_{h}<3 \mathrm{~mm}\right)$ [4,7], have both increased. There are an increasing number of studies on heat transfer and flow resistance in small diameter channels devoted to the process of condensation. The authors use two methods to develop experimental studies. The first is to adapt the correlation verified for conventional channels and apply it to minichannels. The second method is to develop new correlation and computational models based on theoretical or experimental studies performed using minichannels. Correlations useful in the calculation of the heat transfer during condensation in the conventional channel, and applicable for minichannels, include: Akers et al. [1,2], Dobson and Chato [7], Shah [18], Cavallini and Zecchin [8], Tang et al. [21], Thome et al. [22,23], Tandon et al. [20], Moser et al. 
[18], and Wilson et al. [25]. When using any correlation concerning condensation in minichannels, one must always refer to the source material of its origin and compare the parameters of the process and the scope of its verification.

For calculation of the frictional pressure drop, two calculation models, i.e., homogeneous and separated, are used in practice for both the conventional channels and minichannels. The separated model proposes the splitting of two calculation methods: a method of Lockhart-Martinelli [13] and a method due to Friedel [10]. In fact, modifications of these correlations describing the friction pressure drop and the results based on these methods embasked in two directions, i.e., to better define the constant $C$ in the Lockhart-Martinelli equation or determination, usually through the experimental investigations of the real extent of a two-phase correction coefficient $\Phi_{l}^{2}$ of resistance. With respect to the minichannels, the correlations due to Mikielewicz et al. [16], Mishima and Hibiki [17], Tran et al. [24], Lee and Lee, [12], Zhang and Webb [27] or Zhang et al. [26] should be acknowledged. Also deserving acknowledgement of confidence are the correlations of Cavallini and Garimella, which have been documented on a theoretical basis as well as tested experimentally.

There is a need for further experimental and theoretical research in the area of refrigerant transformations in minichannels. This study concerns the physical and mathematical modeling of ecological refrigerant condensation in pipe minichannels of compact heat exchangers. The model was developed in MATLAB environment based on conservation equations.

\section{$2 \quad$ Numerical modeling}

Mathematical modeling using numerical methods allows for calculation of a number of characteristic sizes, including thermal and flow parameters, heat transfer coefficients, and pressure drop along the channel where refrigerants condensate. For several years, researchers all over the world have conducted studies that aim to better understand the mechanism of this process and attempted to develop more accurate theoretical models. Currently, there are only a few proposed models for the condensation of refrigerants in minichannels that are based on reasonable theoretical rules. Moreover, none of them describe the process for a sufficiently large range of parameters. The below authors try to describe the process of refrigerants in a straight axial pipe minichannel. The two-phase system with 
a single component (liquid or gas) is treated as a continuous medium, and the laws of energy, momentum and mass conservation are used to describe the phenomenon. The continuous medium is characterized by parameters describing the two-phase system, such as the two-phase mixture density, void fraction, and vapor quality. In accordance with industry practices, a one-dimensional model, in which the physical quantities are averaged over a cross section of the channel (for average speed, average pressure, average temperature, etc.), is used. The proposed homogeneous model (from non-slip class of models) allows for determination of the values of the basic condensation process parameters, the flow resistance and the heat transfer coefficient over the pipe minichannel length.

\section{Assumptions of the model}

In the proposed model, authors used the following assumptions:

1) straight axial channel is inclined at an angle $\beta$ relative to the level of a two-phase mixture flows one component of the saturation temperature $T_{s}$, the speed of the two phases are equal (slip $s=1$ );

2) fluid flow is turbulent;

3) mass flux density is $G$;

4) mixture has a vapor quality, $x$, and void fraction, $\varphi$;

$5)$ on the whole length of the channel, the constant heat flux is applied;

6) saturated vapor of the refrigerant is supplied to the minichannel;

7) refrigerant condensation process is conducted inside the minichannel. The process is thermally and hydraulically stable in time, that means $\frac{\partial T}{\partial t}=0 ;$

8) longitudinal heat conduction is omitted $\frac{\partial^{2} T}{\partial z^{2}}=0$.

In the model were used conservation equations in the following forms:

- mass conservation equation:

$$
\frac{\partial \rho}{\partial t}+w \frac{\partial \rho}{\partial z}+\rho \frac{\partial w}{\partial \rho}=-\rho w \frac{1}{A} \frac{\partial A}{\partial z},
$$

- energy conservation equation:

$$
\rho \frac{\partial h}{\partial t}-\frac{\partial p}{\partial t}+\rho w \frac{\partial h}{\partial z}-w \frac{\partial p}{\partial z}=\frac{\tau_{w} w C}{A}+\frac{q_{w} C}{A},
$$


- momentum conservation equation:

$$
\rho \frac{\partial w}{\partial t}+\rho w \frac{\partial w}{\partial z}=\rho g \cos \beta-\frac{\tau_{w} C}{A}-\frac{\partial p}{\partial z} .
$$

The equation of state has the form of

$$
\rho=\rho(h, p) .
$$

If the system is in steady state, the mass conservation equation (1) is in the 'integral of mass' form:

$$
w \rho A=G A=\dot{m}=\text { const } .
$$

After taking this into account the equation take the form:

$$
\begin{gathered}
-\frac{d p}{d z}+\rho \frac{d h}{d z}=\frac{\tau_{w} C}{A}+\frac{q_{w} \rho C}{\dot{m}}, \\
\left(1-\frac{\dot{m} D_{1}}{A^{2} \rho^{2}}\right) \frac{d P}{d z}-\frac{\dot{m} D_{2}}{A^{2} \rho^{2}} \frac{d h}{d z}=\frac{\dot{m}}{A^{3} \rho d z}+g \rho \cos \beta-\frac{\tau_{w} C}{A},
\end{gathered}
$$

where

$$
D_{1}=\left(\frac{\partial \rho}{\partial p}\right)_{h}, \quad D_{2}=\left(\frac{\partial \rho}{\partial h}\right)_{p} .
$$

It is a system of ordinary differential equations containing the equations of energy balance, momentum and mass transfer equation of state (7) and the closure equations describing the heat flux density, $q_{w}$, and shear stress, $\tau_{w}$, on the inner wall of the channel.

\subsection{The closing equations}

Correlation describing the shear stress, $\tau_{w}$, on the inner wall of the channel was assumed as the closure equation:

$$
\tau_{w}=\frac{\mu_{l} w_{l}}{w_{H}} .
$$

Equation (10) allows to calculate the frictional pressure drop which is balanced by shear stress on the wall of the channel:

$$
\left[\frac{d p}{d z}\right]_{T P F}=\frac{C}{A} \tau_{w},
$$


where: $C$ - wetted perimeter, $C=\pi d_{h}, d_{h}$ - minichannel hydraulic diameter, $A$ - cross sectional area, $\tau$ in - shear stress.

The thickness of the hydraulic boundary sublayer, $\delta_{H}$, defines the relationship

$$
\delta_{H}=\frac{2 \mu_{l}}{f w_{l} \rho_{l}},
$$

where $f$ is the Fanning coefficient defined for transitional flow by the formula

$$
f=\frac{0.316}{4} \mathrm{Re}^{-0.25} \text {. }
$$

Velocity of the liquid phase can be calculated from the relationship

$$
w_{l}=\frac{G}{\rho_{l}}\left(\frac{1-x}{1-\varphi}\right),
$$

where: $G$ - mass flux density, $\rho_{l}$ - density of the liquid phase, $x$-vapor quality, $\varphi$ - void fraction.

After substitution of Eqs. (12) and (13) to formula (11) obtained

$$
\left[\frac{d p}{d z}\right]_{T P F}=0.16 \frac{\operatorname{Re}^{-0.25}(w \rho)}{d_{h} \rho_{l}}\left(\frac{1-x}{1-\varphi}\right) .
$$

The vapor quality $x$ is determined from the following equation:

$$
x_{n}=x_{n-1}-\frac{q_{w}}{G r},
$$

where $r$ is the latent heat of the two-phase change process.

The homogeneous model assumes that the gas and liquid phases do not interact with each other in any way, which causes the divergence of the calculated results based on this model from the experimental results. In fact, there is a movement resulting from the turbulence of the gas phase. This causes the increase of shear stresses. For this reason, shear stresses were corrected by the correcting factor $B$ :

$$
\tau_{w}{ }^{\prime}=\tau_{w} B
$$

where

$$
B=2(1-x)^{0.8}+0.008 \operatorname{Re}^{0.75} \operatorname{Pr}^{-2.5} .
$$

The value of coefficient $B$ was determined by the method of matching the results of theoretical calculations to experimental results. After taking into account Eq. (16), the relationship for the friction pressure drop is obtained via

$$
\left[\frac{d p}{d z}\right]_{T P F}=0.16 \frac{\operatorname{Re}^{-0.25} w \rho}{d_{h} \rho_{l}}\left(\frac{1-x}{1-\varphi}\right) B .
$$




\section{The modeling result}

Based on the proposed model, describing the process of refrigerants condensation in pipe minichannels carried out were numerical calculations. It was possible to determine the flow resistance, $\Delta p / z$, change of pressure, $p / z$; refrigerant temperature, $T$, temperature of the minichannel wall, $T_{w}$, the vapor quality, $x$, and the void fraction, $\varphi$, in the refrigerant flow. Figures 1-6 show an example of the theoretically calculated results of the condensation parameters of the R134a refrigerant in channels with an internal diameter $d_{h}=1.94 \mathrm{~mm}$ and $0.64 \mathrm{~mm}$. Calculations were performed for the following parameters: $d_{h}=1.94 \mathrm{~mm}$, saturation temperature at the inlet to the channel $T_{s}=42{ }^{\circ} \mathrm{C}$, heat flux $q=30000 \mathrm{~W} / \mathrm{m}^{2}$, mass flux $G=451$; $376 ; 282$, and $188 \mathrm{~kg} / \mathrm{m}^{2} \mathrm{~s}$, for $d_{h}=0.64 \mathrm{~mm}$ parameters were as follows: $T_{s}=42.5^{\circ} \mathrm{C}, q=30000 \mathrm{~W} / \mathrm{m}^{2}$ and $G=950 ; 691$ and $431 \mathrm{~kg} / \mathrm{m}^{2} \mathrm{~s}$.

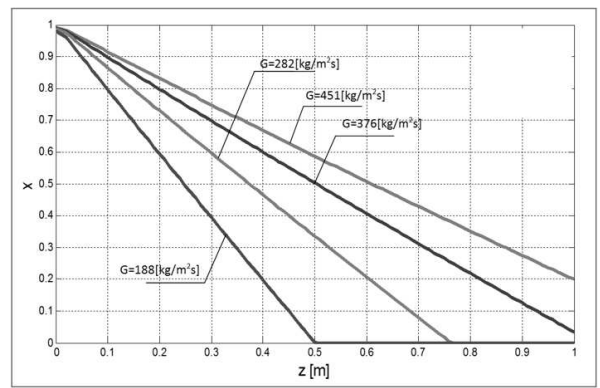

a)

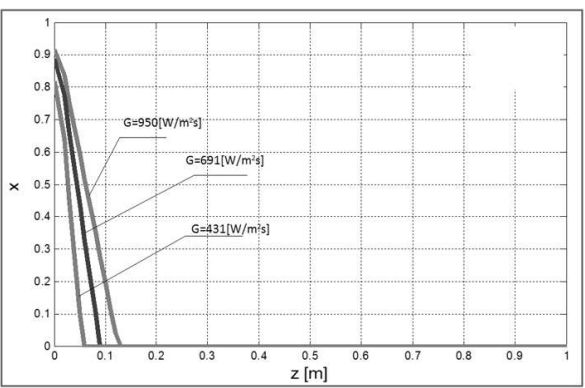

b)

Figure 1: The results of theoretical calculations of vapor quality, $x$, changes on the length of the channel, for selected mass fluxes $G$ : a) $d_{h}=1.94 \mathrm{~mm}$, b) $d_{h}=0.64 \mathrm{~mm}$.

Conducted calculations show that, with the decrease of vapor quality, $x$, the void fraction, $\varphi$, temperature, $T$, and pressure, $p$, of the refrigerant all decrease. On the other hand the flow resistance increase, from the beginning of the condensation to the development of the process. When the content of the liquid phase in the flow increases, the flow resistance decreases rapidly to a value tens of times lower than the maximum. 


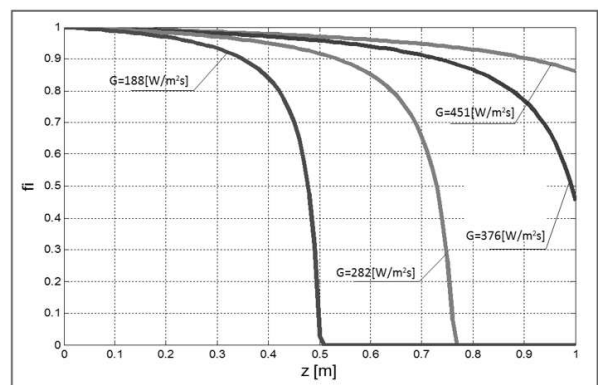

a)

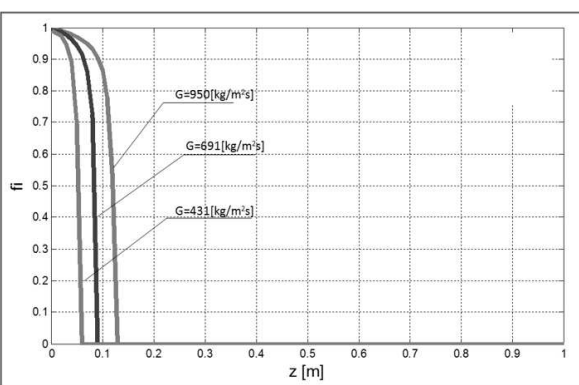

b)

Figure 2: Results of theoretical calculations of the void fraction, $\varphi$, changes on the channel length $z$, for few mass fluxes $G$ : a) $d_{h}=1.94 \mathrm{~mm}$, b) $d_{h}=0.64 \mathrm{~mm}$.

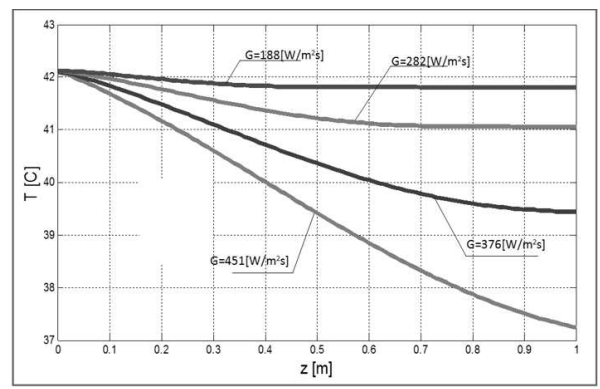

a)

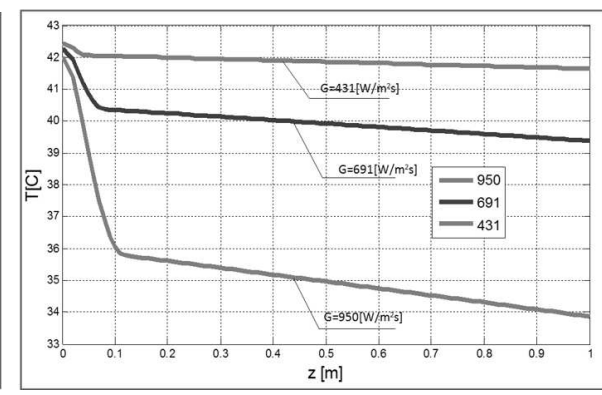

b)

Figure 3: Results of theoretical calculations of the refrigerant temperature, $T$, changes on the length of the channel $z$, for few mass fluxes $G$ : a) $d_{h}=1.94 \mathrm{~mm}$, b) $d_{h}=0.64 \mathrm{~mm}$.

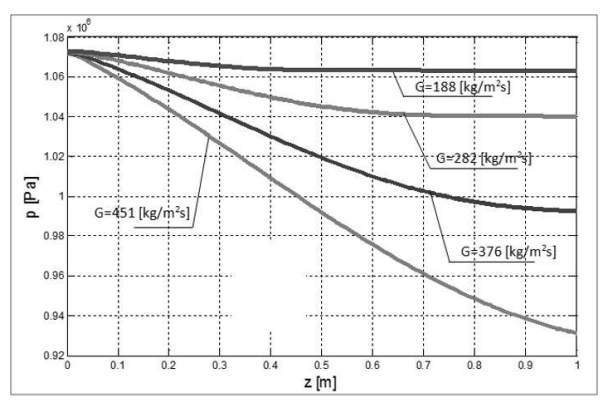

a)

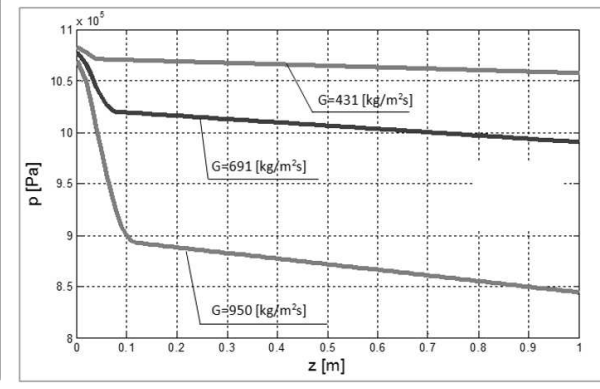

b)

Figure 4: Results of theoretical calculations of the refrigerant pressure, $p$, changes on the length of the channel $z$, for few mass fluxes $G$ : a) $d_{h}=1.94 \mathrm{~mm}$, b) $d_{h}=0.64 \mathrm{~mm}$ 


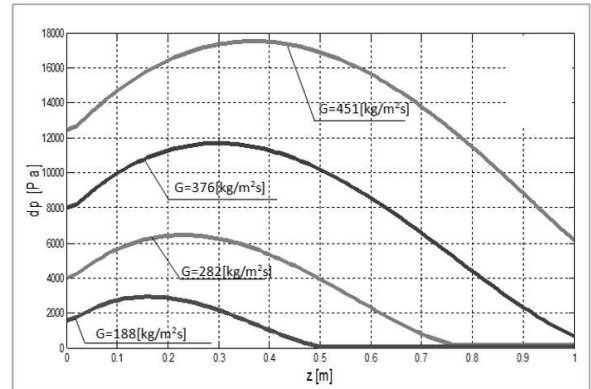

a)

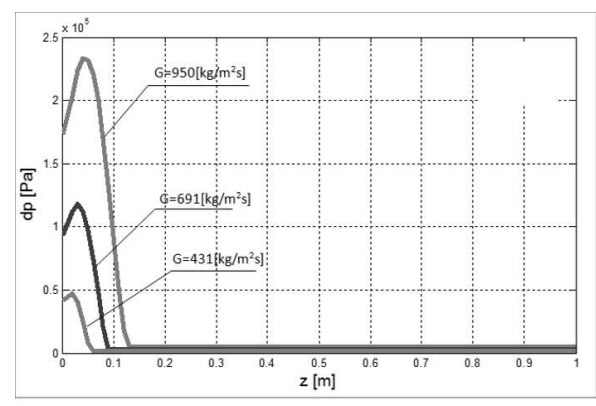

b)

Figure 5: Results of theoretical calculations of the refrigerant flow resistance, $d p$, changes on the length of the channel, $z$, for few mass fluxes $G$ : a) $d_{h}=1.94 \mathrm{~mm}$, b) $d_{h}=0.64 \mathrm{~mm}$.

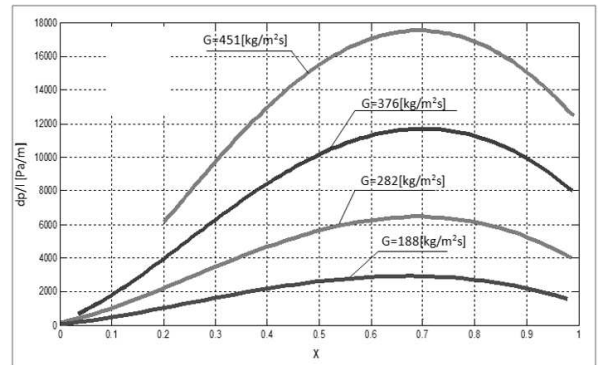

a)

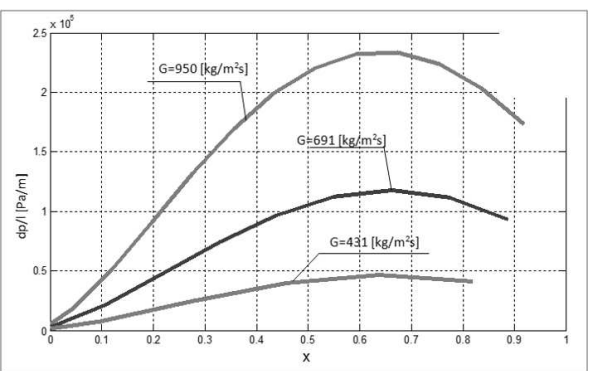

b)

Figure 6: Dependence of theoretical refrigerant flow resistance, $d p / l$, on the vapor quality, $x$, for few mass flux densities $G$; a) $d_{h}=1.94 \mathrm{~mm}$, b) $d_{h}=0.64 \mathrm{~mm}$.

\section{Comparison of the results of model calculations with experimental results}

Figure 7 presents a comparison between the computational model of the flow resistance, $\Delta p / L$, dependence on the vapor quality, $x$, and the experimental results. As observed, the results of calculations by the model satisfactorily describe the flow resistance during condensation of refrigerants, but, if vapor quality decreases below the value of 0.2 , the discrepancy between the mathematical model and the experimental results increases. This is caused by the occurrence of a small amount of the gas phase and 
a significant decrease in the interaction of the refrigerant phases. Figure 8 shows a comparison between the calculated results of the vapor quality on the length of the channel and the experimental results.

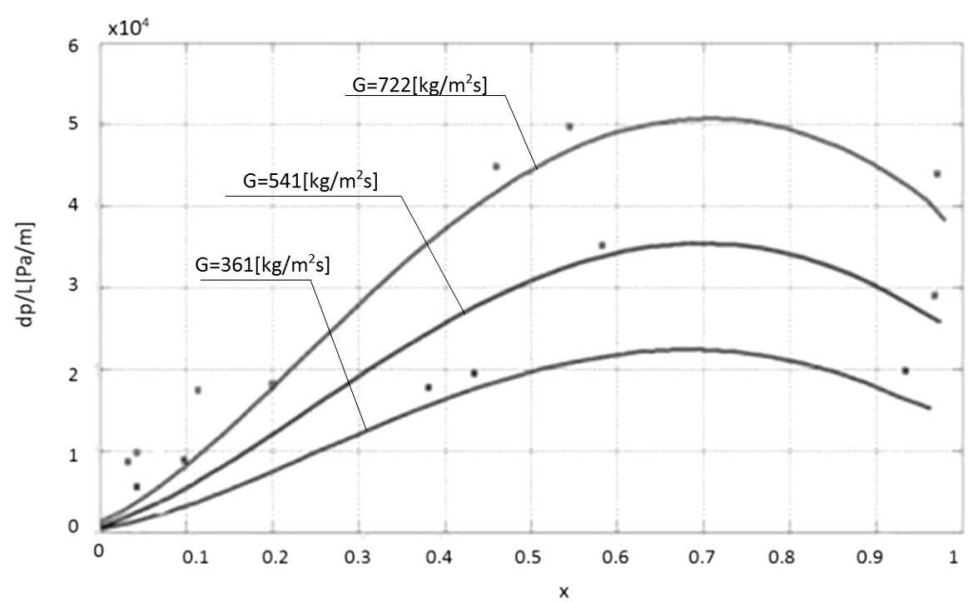

Figure 7: Comparison of calculated by the model flow resistance, $d p / l$, and values from experimental investigations, during condensation of R134a refrigerant in pipe minichannel with an internal diameter $d_{h}=1.4 \mathrm{~mm}$, with changes of the vapor quality, $x$, in the whole range, for few mass fluxes, $G$.

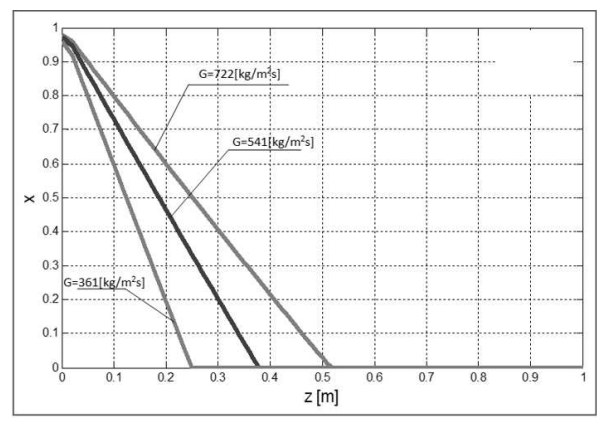

a)

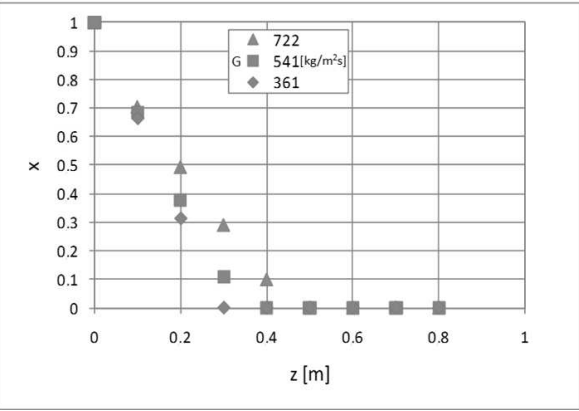

b)

Figure 8: Summary of the vapor quality $x$ changes during condensation of R134a refrigerant in pipe minichannel with internal diameter $d_{h}=1.4 \mathrm{~mm}$ on the length of the channel, for few mass fluxes, $G$ : a) according to theoretical calculations, b) according to the experimental tests.

Figure 9 shows a comparison between the modeling results and the experimental results for refrigerant R134a, R404A and R407C condensation. 


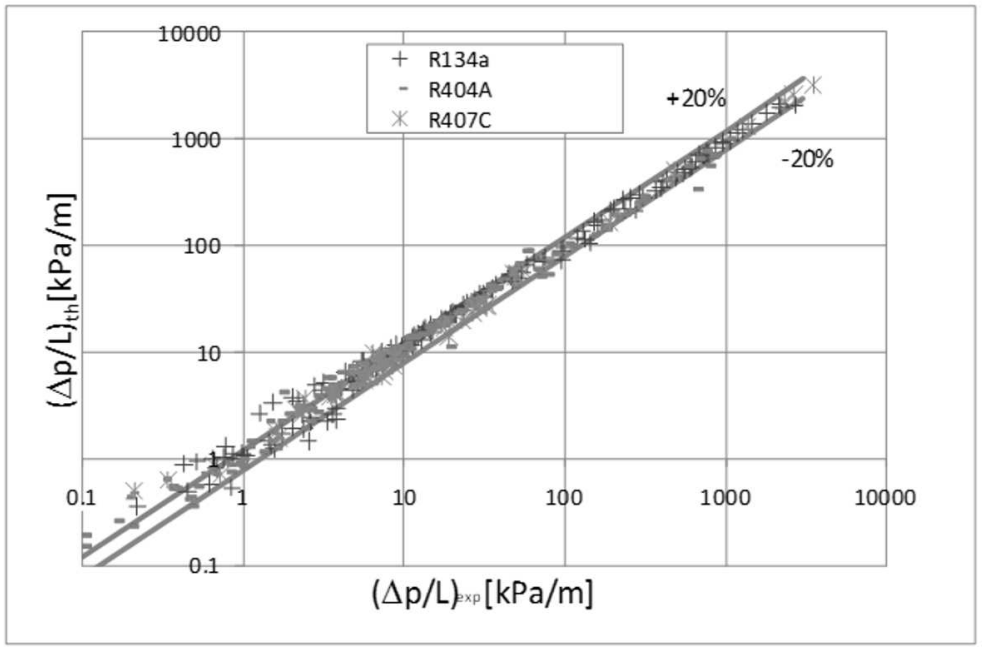

Figure 9: Comparison of modeling results with the experimental studies' results of condensation in the pipe minichannels for refrigerants: R134a, R404A and R407C in terms of flow resistance.

This comparison shows that $80 \%$ of the measuring points are in the range of $\pm 20 \%$. It can be concluded that the proposed model appropriately describes the experimental results with an accuracy of $\pm 20 \%$ for condensing in a wide range of changes in process parameters. A model is used to determine the value of parameters describing the condensation process of the refrigerant in the pipe minichannel, including the flow resistance values. It can be used in engineering work to design compact heat exchangers.

\section{Conclusions}

1. Authors' own model describing the refrigerant condensation process in pipe minichannels was presented. In accordance with industry practices, a one-dimensional model, in which the physical quantities are averaged over a cross-section of the channel, was used. The proposed homogeneous model allows us to determine the values of the basic parameters of the condensation process, including the flow resistance over the length of the pipe minichannel. The proposed model recognizes the following important considerations: during the twophase refrigerant flow in the pipe minichannels are flow resistances, the values of which are many times higher than those obtained in the 
single-phase flow at the same flow rate, and the vapor phase, occurring during the condensation process, causes turbulence in this flow, which affects the growth of the flow resistance volume.

2. The model adequately describes the refrigerants condensation process in pipe minichannels. Obtained results of the flow resistance calculations from the model were compared with experimental results. Their compatibility was satisfactory in the range of $\pm 20 \%$.

3. It is proposed to use a developed model for the calculation of characteristic parameters of the condensation process of refrigerants R134a, R404A, R407C in pipe minichannels with an internal diameter of $0.64-3.3 \mathrm{~mm}$. The value ranges of the process parameters should be: mass flux density $50-1000 \mathrm{~kg} /\left(\mathrm{m}^{2} \mathrm{~s}\right)$, saturation temperature 30 $50{ }^{\circ} \mathrm{C}$, the vapor quality $0-1$.

Received 2 October 2017

\section{References}

[1] Akers W., Deans O.K., Crosser O.K.: Condensation heat transfer within horizontal tubes. Chem. Eng. Progr. 54(1958), 89-90.

[2] Akers W., Deans O.K., Crosser O.K.: Condensation heat transfer within horizontal tubes. Chemical Engineering Progress Symp. 55(1959), 171-176.

[3] Bohdal T., Charun H., Sikora M.: Comparative investigations of the condensation of $R 134$ a and $R 404 A$ refrigerants in pipe minichannels. Int. J. Heat Mass Tran. 54(2011), 1963-1974

[4] BOHDAL T.: Investigations of environmentally friendly refrigerants phase changes in minichannels. Annual Set the Environment Protection 15(2013), 107-126.

[5] Bohdal T., Charun H., Sikora M.: Empirical study of heterogeneous refrigerant condensation in pipe minichannels. Int. J. Refrig. 59(2015), 210-223.

[6] Bohdal T., Widomska K., Sikora M.: The analysis of thermal and flow characteristics of the condensation of refrigerant zeotropic mixtures in minichannels. Arch. Thermodyn. 37(2016), 2, 41-69.

[7] Cavallini A., Del Col D., Matkovic M., Rossetto L.: Frictional pressure drop during vapour-liquid flow in minichannels: Modelling and experimental evaluation. Int. J. Heat Fluid Fl. 30(2009), 131-139.

[8] Cavallini A., Zecchin R.: A dimensionless correlation for heat transfer in forced convection condensation. In: Proc. 6th Int. Heat Transfer Conf., Tokyo, 3(1974), 309-313.

[9] Dobson M.K., Chato J.C.: Condensation in smooth horizontal tubes. J. Heat Trans-T ASME 120(1998), 1, 193-213. 
[10] FRIEDEL L.: Improved friction pressure drop correlation for horizontal and vertical two-phase pipe flow. European Two-Phase Flow Group Meeting, Ispra 1987, Paper 2 .

[11] Kharangate C. R., Mudawar I.: Review of computational studies on boiling and condensation. Int. J. Heat Mass Tran. 108(2017), 1164-1196.

[12] LeE H.J., LEE S.Y.: Pressure drop correlations for two-phase flow within horizontal rectangular channels with small heights. Int. J. Multiphas. Flow 27(2001), 783-796.

[13] Lockhart R.W.: Martinelli R.C.: Proposed correlation of data for isothermal two-phase, two-component flow in pipes. Chem. Eng. Prog. 45(1949), 1, 39-48.

[14] Mikielewicz J.: Domestic combined micro heat and power plant. Annual Set of the Environment Protection 11(2009), 25-38.

[15] Mikielewicz J., Mikielewicz D.: The dynamics of heat exchangers and instabilities in ORC circulation. Annual Set of the Environment Protection 13(2011), 425-440.

[16] Mikielewicz D., Wajs J., Andrzejczyk R., Klugmann M.:Pressure drop of HFE7000 and HFE7100 during flow condensation in minichannels. Int. J. Refrig. 68(2016), 226-241.

[17] Mishima K., Hibiki T.: Some characteristics af air-water flow in small diameter vertical tubes. Int. J. Multiphas. Flow 22(1996), 703-712.

[18] Moser K., WebB R.L., NA B.: A new equivalent Reynolds number model for condensation in smooth tubes. J. Heat Trans.-T ASME 120(1998), 410-417.

[19] Sнaн M.M.: A general correlation for heat transfer during film condensation inside pipes. Int. J. Heat Mass Tran. 22(1979), 547-556.

[20] Tandon T.N., Varrna H.K., Gupta C.P.: New flow regimes map for condensation inside horizontal tubes. J. Heat Trans.-T ASME 104(1982), 4, 763-768.

[21] TANG L.: Empirical Study of New Refrigerant Flow Condensation Inside Horizontal Smooth and Micro-Fin Tubes. University of Maryland, College Park, 1997.

[22] Thome J.R., El Hajal J., Cavallini A.: Condensation in horizontal tubes, PART 1: TWO - PHASE FlOW PATtERn map. Int. J. Heat Mass Tran. 46(2003), 18, 3349-3363.

[23] Thome J.R., El Hajal J., Cavallini A.: Condensation in horizontal tubes, part 2: new heat transfer model based on flow regimes. Int. J. Heat Mass Tran. 46(2003), $18,3365-3387$.

[24] Tran T.N., Chyu M.C., Wambsganss M.W., France D.M.: Two-phase pressure drop of refrigerants during flow boiling in small channels. Int. J. Multiphas. Flow 26(2000), 11, 1739-1754.

[25] Wilson M.J., Newell T.A., Chato J.C., Ferreira C.A.: Refrigerant charge, pressure drop and condensation heat transfer in flattened tubes. Int. J. Refrig. 26(2003), 4, 442-451.

[26] Zhang W., Hibiki T., Mishima K.: Correlations of two-phase frictional pressure drop and void fraction in mini-channel. Int. J. Heat Mass Tran. 53(2010), 453-465.

[27] Zhang M., WebB R.L.: Correlation of two-phase friction for refrigerants in smalldiameter tubes. Exp. Therm. Fluid Sci. 25(2001), 3-4, 131-139. 